\title{
Монолитные сорбенты с ковалентно связанной матрицей для тонкослойной хроматографии в сочетании с масс-спектрометрией с матрично- активированной лазерной десорбцией/ионизацией
}

\author{
(C) 2019 Кучеренко Е.В. ${ }^{1}$, Канатьева А.Ю. ${ }^{2}$, Курганов А.А. ${ }^{2}$, \\ Борисов Р.С. ${ }^{2}$, Пирогов А.В. ${ }^{1}$ \\ ${ }^{1}$ Московский государственный университет им. М.В. Ломоносова, Москва \\ ${ }^{2}$ Институт нефтехимического синтеза им. А.В. Топчиева Российской академии наук, Москва
}

Поступила в редакцию 17.06.2019 г.

DOI: $10.17308 /$ sorpchrom.2019.19/2225

Показана возможность создания монолитных пластин, содержащих в своей структуре функциональные группы, способные выполнять роль МАЛДИ матриц, продемонстрированы первые результаты по десорбции/ионизации соединений с массами порядка 400 Да. Приготовлены монолитные пластины на основе (со)полимеров глицидилметакрилата и этиленгликоля диметакрилата с содержанием первого от 0 до 29\% и стирола и дивинилбензола с содержанием стирола от 0 до $35 \%$. Наилучшие результаты удалось получить для пластин с содержанием глицидилметакрилата от 19 до 29 \% и с содержанием стирола 5-20\%. Отмечено, что отсутствие монофункционального мономера в полимеризационной смеси приводит к подавлению ионизации аналитов и невозможности использования таких пластин в режиме МАЛДИ-МС. Предложенный в работе метод получения МАЛДИ-МС-ТСХ спектров позволяет исключить один из наиболее трудоемких этапов процесса, связанный с приготовлением и нанесением МАЛДИ матрицы на ТСХ платины.

Ключевые слова: ТСХ, МАЛДИ, хроматография, монолитные сорбенты, структура поверхности, сорбция.

\section{Monolithic sorbents with covalently bonded matrix for thin layer chromatography coupled with matrix-assisted laser desorption/ ionization}

(C) 2019 Kucherenko E.V. ${ }^{1}$, Kanateva A.Yu. ${ }^{2}$, Kurganov A.A., Borisov R.S. ${ }^{2}$, Pirogov A.V. ${ }^{1}$

${ }^{1} \mathrm{MSU}$, Moscow

${ }^{2}$ A.V. Topchiev Institute of Petrochemical Synthesis, Moscow

The possibility of creating monolithic plates containing functional groups capable of performing the role of MALDI matrices is shown, and the first results on desorption / ionization of compounds with masses of the order of $400 \mathrm{Da}$ are demonstrated. Monolithic plates were prepared based on (co)polymers of glycidyl methacrylate and ethylene glycol dimethacrylate with the content of the first from 0 to $29 \%$ and styrene and divinylbenzene with the content of styrene from 0 to $35 \%$. The best results were obtained for TLC plates with glycidyl methacrylate content from 19 to $29 \%$ and with a styrene content of 5 to $20 \%$. It is noted that the absence of a monofunctional monomer in the polymerization mixture resulted in the suppression of analyte ionization and the impossibility of using such TLC plates in the MALDI-MS mode. Another factor affecting 
the possibility of desorption/ionization of compounds is the quality of the surface. The presence of roughness, uneven surface dramatically affect the ability to work in the mode of MALDI-MS, and the monoliths, containing less than $19 \%$ of the GMA, were mechanically fragile, and manipulation with them easily led to surface damage. Similar results were obtained for monolithic sorbents based on (co)polymers of styrene and divinylbenzene with styrene percentage lower than $10 \%$. In order to obtain information on the surface relief, monolithic layers were prepared on glass substrates $(18 \times 18 \mathrm{~mm}, 0.13-0.17 \mathrm{~mm}$ thick $)$ with various contents of monofunctional monomers and using various porogens and were studied by scanning electron microscopy. According to the height distribution histograms, it was found that for a sample of St-DVB copolymer containing 30\% styrene and 10\% divinylbenzene in the initial polymerization mixture (undecanol-toluene solvent 52:8) the highest density corresponded to an average roughness value of $150 \mathrm{~nm}$, whereas for sample composition (14\% GMA + 26\% DMEG, 60\% cyclohexanol), the highest density corresponded to an average roughness value of 50-60 $\mathrm{nm}$. The proposed method for obtaining MALDI-MS-TLC spectra eliminates one of the most labor-intensive stages of the process associated with the preparation and application of the MALDI matrix on a TLC plate.

Keywords: TLC, MALDI, chromatography, monolithic sorbents, surface structure, sorption

\section{Введение}

Матрично активированная лазерная десорбция-ионизация (МАЛДИ) представляет собой относительно новый масс-спектральный метод, успешно решивший проблему сложной ионизации низколетучих и термолабильных соединений, таких, например, как биологические макромолекулы $[1,2]$. Метод широко используется в биохимических исследованиях, геномике, протеомике [3-5]. Одной из наиболее важных проблем метода является мешающее влияние ионов, генерируемых собственно матрицей в области малых молекулярных масс, обычно - ниже 400 Да. Именно по этой причине этот метод мало используется для анализа низкомолекулярных соединений. Для решения этой проблемы в литературе предложены различные способы модификации матричных соединений. Так, для анализа низкомолекулярных соединений в работе [6] были использованы модифицированные пористые силиконовые частицы SBA-15 вида ([CHC $\left.\left.{ }^{-}\right]\left[\mathrm{NH}^{3+}-\mathrm{Si}-\mathrm{SBA}-15-\mathrm{Si}_{-} \mathrm{NH}^{3+}\right]\left[\mathrm{CHC}^{-}\right]\right)$, которые были синтезированы путем ковалентного связывания полимера SBA-15 с ионной жидкостью, образованной $\alpha$-циано-4-гидрокси коричной кислотой (ЦГКК, СНСА) и 3-аминопропилтриэтоксисиланом (3-APTES). Полученная матрица обладала определенными преимуществами при анализе меламина: минимальным фоновым сигналом мешающих ионов, высокой гомогенностью, обеспечивала повышенную чувствительность и высокую воспроизводимость. С использованием предложенной матрицы авторы [6] предложили новый метод анализа меламина в пробах молока с использованием МАЛДИ-МС детектирования и провели оценку влияния дополнительных факторов: концентрации суспензии матрицы, соотношения матрица - образец, методов нанесения и высушивания, различных способов приготовления пробы. В оптимальных условиях авторам [6] удалось достичь достаточно низкого предела детектирования меламина в составе молока $(0.1$ мг/кг) и высокой воспроизводимости $(\mathrm{CO} \leq 14 \%)$.

В работе [7] также развивается идея приготовления модифицированных матриц путем иммобилизации классических «матричных» соединений МАЛДИ на крупных частицах силикагеля с целью обеспечения возможности анализа низкомолекулярных соединений с массами до 600 Да. Авторы проводят ковалентное связывание прекурсора ионных жидкостей, например, силилированного амина, с силикагелевой основой, после чего происходит взаимодействие полученной системы с анионом традиционного матричного соединения ЦГКК с образованием анионного макрокомплекса (рис. 1). Полученная авторами [7] модифицированная матрица продемонстрировала два основных преимущества: иммобилизация молекулы ЦГКК не влияет на область поглощения этой молекулы, максимум поглощения остается неиз-

Кучеренко и др. / Сорбционные и хроматографические процессы. 2019. Т. 19. № 6. С. 645-655 
менным и соответствует 328 нм. Это позволяет использовать новую матрицу в стандартных МАЛДИ-МС системах с азотными лазерами. Во-вторых, ковалентное закрепление катионной части ионной жидкости на силикагеле позволяет избежать шума матрицы в низкомолекулярной области в режиме фиксации положительных ионов.

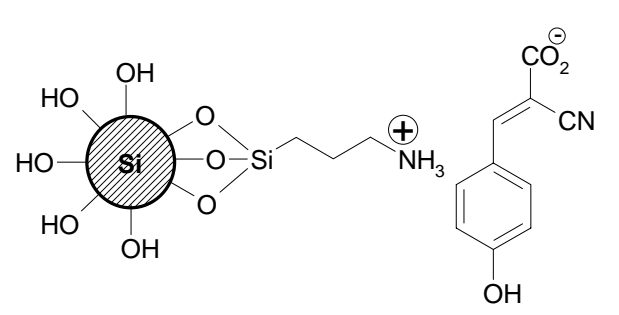

.a

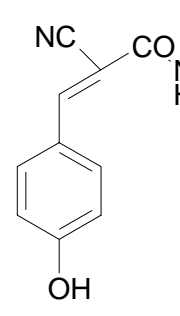

Рис. 1. Модифицированная высокомолекулярная матрица для МАЛДИ-МС анализа низкомолекулярных соединений А) на основе ковалентно закрепленной ионной жидкости [7]; Б) с углеводородным спейсером [8].

Возможность использования новых матриц для анализа небольших молекул была успешно проверена авторами [7] на примере определения двух нейротрансмиттеров - дофамина (153.08 Да) и серотонина (176.09 Да).

B работе [8] описано использование модифицированной матрицы SBA-15APTES-CHCA со спейсером для анализа небольших молекул (рис. 1). Согласно авторам [8], 3- APTES, выступающий в роли спейсера, обеспечивает наличие гибкой углеводородной цепи, давая возможность фрагментам молекул ЦГКК распределяться по поверхности SBA-15, что увеличивает емкость матрицы с точки зрения поглощения энергии, а также облегчает ее сокристаллизацию с пробой. Такая матрица более стабильна, чем используемые в аналогичных целях анионные макрокомплексы, и может подвергаться вакуумной сушке и сушке на воздухе, в течение долгого времени хранится в виде готового порошка. Авторами [8] было проведено определение 12 антибиотиков - производных хинолона с молекулярными массами от 319 до 441 Да (данофлоксацин, энрофлоксацин, ципрофлоксацин, дифлоксацин, эноксацин, гатифлоксацин, флероксацин, ломефлоксацин, спарфлоксацин, норфлоксацин, левофлоксацин, пефлоксацин) и трех пестицидов с молекулярными массами от 191 до 362 Да (кумафос, фенобукарб, карбендазим). На рис. 2 показан МАЛДИ масс-спектр производных хинолона с использованием предлагаемой авторами [8] матрицы.
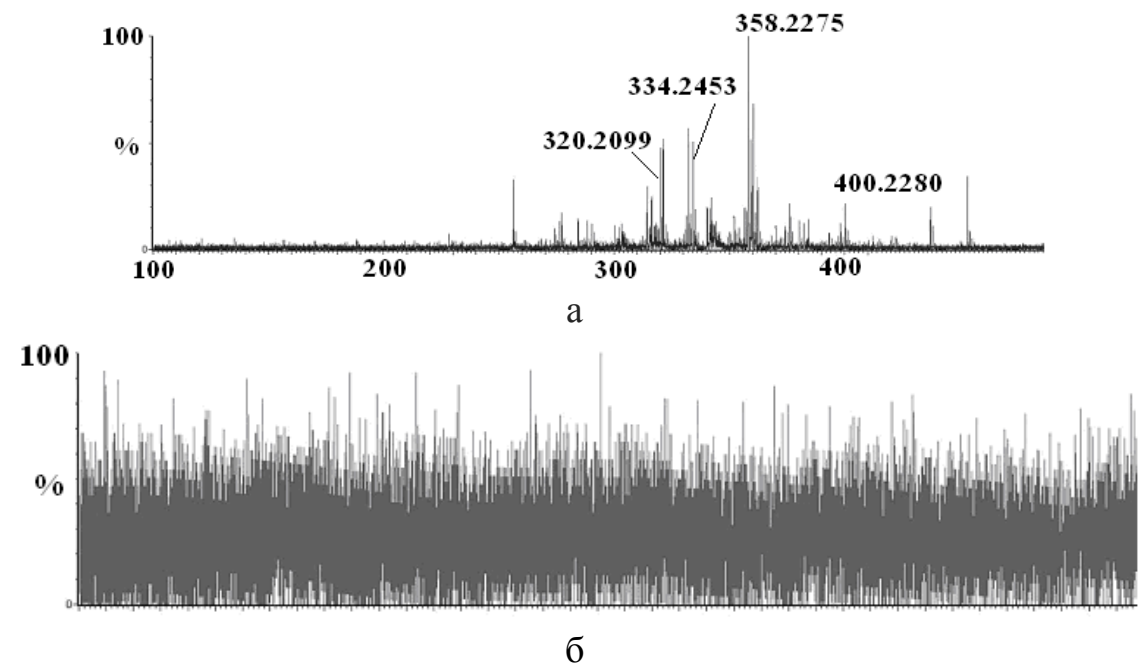

Рис. 2. МАЛДИ масс-спектр производных хинолона (1 мг/дм³): А) с использованием SBA-15-APTES-CHCA матрицы; Б) без использования матрицы [8]. 
Как видно из рис. 2, использование высокомолекулярной матрицы в данном случае позволяет исключить фоновый шум в области молекулярных масс до 480 Да и при этом успешно ионизировать и определять низкомолекулярные соединения.

Наилучшие результаты при использовании масс-спектрометрических методов, в том числе и МАЛДИ, удается достичь при определении индивидуальных соединений или максимально простых смесей. Единственным методом разделения, напрямую сочетающимся с системой МАЛДИ-МС, является тонкослойная хроматография (ТCX), и в литературе имеется большое количество работ по оптимизации процедуры сопряжения ТСХ-МАЛДИ-МС. Так, в работе [9] авторы определяли азотсодержащие гетероциклические соединения с ММ до 500 Да с использованием ТСХ-МАЛДИ-МС. После предварительного разделения аналитов авторы использовали различные смеси классических МАЛДИ матриц и частиц графита, диспергированных в глицерине, для регистрации масс-спектров МАЛДИ непосредственно с TCX пластин. Авторам удалось успешно визуализировать ТCX хроматограммы, увеличить эффективность десорбции и ионизации, предотвратить вторичное элюирование пятна пробы, упростить и ускорить пробоподготовку. Например, при определении препарата Варденафил (ММ=488 Да) соотношение сигнал/шум увеличилось более, чем в 35 раз (с 22 до 821) при переходе от антрацентриола к предлагаемой авторами [9] матрице.

Авторы работы [10] использовали сочетание ТСХ-МАЛДИ-МС для мониторинга синтеза производных полиамидоаминов - синтетических дендримеров, успешно используемых в биомедицинских областях для транспорта лекарств. Процедура включала в себя поиск и идентификацию побочных продуктов синтеза дендримеров, в том числе и низкомолекулярных соединений. Авторам удалось успешно обнаружить и предположить структуру нескольких побочных продуктов, в том числе и c $\mathrm{MM}=527$ Да в виде ионов $[\mathrm{M}+\mathrm{H}]+$ и $[\mathrm{M}+\mathrm{Na}]+(\mathrm{m} / \mathrm{z}=528.4$ и 550.4 , соответственно). Определение более низкомолекулярных аналитов оказалось невозможным при использованном авторами [10] оборудовании.

Интересный вариант сочетания МАЛДИ-МС и ТСХ предложен в работе [11], где авторы использовали метод для скрининга биологически активных веществ в растительных экстрактах. При этом ТСХ использовали для разделения и количественного определения компонентов пробы в сочетании с УФ-детектированием, а МАЛДИ-МС затем выборочно применяли для идентификации разделенных соединений. В качестве матрицы авторы [11] использовали поверхностнослойные наночастицы оксида железа, покрытые силикагелем, что позволило успешно ионизировать и определить БАВ с соотношением $\mathrm{m} / \mathrm{z}$ до 500 Да, а также продукты их гидролиза с $\mathrm{m} / \mathrm{z}=203$. При этом ТСX пластину перед разделением компонентов приходилось предварительно трижды погружать в раствор МАЛДИ матрицы в этаноле, после чего высушивать для создания равномерного слоя матрицы на пластине и лишь затем проводить хроматографические разделения.

Таким образом, при сочетании ТСХ и МАЛДИ-МС перед исследователем встают две основные проблемы: необходимость пробоподготовки, главным образом - нанесения матрицы на ТСХ пластину до или после хроматографического разделения, минимально влияющей на полученное разделение компонентов пробы, а также необходимость получения новых матриц, дающих возможность определения низкомолекулярных соединений. В связи с этим целью настоящей работы является получение монолитных сорбентов для ТСХ, позволяющих проводить разделение в тонком слое и напрямую сочетающихся с системой МАЛДИ-МС детектирования без дополнительной стадии пробоподготовки в виде нанесения матрицы. Это подразумевает введение в структуру монолита функциональных групп, способных выпол- 
нять функции матрицы. Фоновый сигнал при этом должен быть сведен к минимуму за счет нахождения функциональных групп в структуре полимерного монолитного сорбента.

\section{Эксперимент}

Приготовление пластин с монолитным сорбентом. Синтез монолитных сорбентов проводили в два этапа. На первом этапе осуществляли подготовку поверхности стеклянных или кремниевых пластин, выступающих в роли подложек. Для этого пластину погружали в 34\% раствор хлороводородной кислоты на 30 мин, после чего промывали деионизированной водой, затем обрабатывали 0.1 М раствором гидроксида натрия в течение 40 мин, снова промывали деионизированной водой и высушивали в течение часа при $100^{\circ} \mathrm{C}$. Активированная таким образом пластина подвергалась силанизации для обеспечения последующего ковалентного связывания монолита с поверхностью подложки. Для этого ее погружали в 30\% (масс.) раствор 3-(триметоксисилил) пропилметакрилата на 24 часа, затем промывали ацетоном и высушивали в течение 1 ч при $40^{\circ} \mathrm{C}$. Силанизированную пластину помещали в прессформу, которую заполняли полимеризационным раствором, после чего проводили термо- или фотоинициированную полимеризацию. Полимеризационную смесь готовили растворением инициатора в смеси мономера и порообразователя. В качестве мономеров использовали этиленгликоль диметакрилат (ДМЭГ) и глицидилметакрилат (ГМА), а также смеси ДМЭГ/ГМА в различных соотношениях. В качестве инициатора радикальной полимеризации, как при термической, так и при фотоионизации, использовали 2,2'-азодиизобутиронитрил (АИБН) в количестве $1 \%$ (масс.) от количества мономеров (смеси мономеров). Все использованные реактивы были приобретены у Fluka (Австрия), Sigma Aldrich Chemical Co. (США), ЗАО «Экрос» (Россия) и ЗАО «Вектон» (Россия). Условия полимеризации и составы полимеризационных смесей приведены в таблице 1. Готовые ТСХ пластины промывали растворителями и просушивали в течение 1 ч при $100^{\circ} \mathrm{C}$. В итоге было получено порядка 100 различных ТСX пластин с монолитными сорбентами, наиболее подходящие из которых затем были проверены в МАЛДИ-МС.

Таблица 1. Условия полимеризации и составы полимеризационных смесей, использованные в работе

\begin{tabular}{|c|c|c|}
\hline Мономер(ы) & Порообразователь & Условия полимеризации \\
\hline \multirow{2}{*}{ ДМЭГ } & \multirow{2}{*}{$\begin{array}{c}\text { додеканол : толуол } \\
(52: 8) / \text { циклогексанол }\end{array}$} & $70^{\circ} \mathrm{C}, 3$ ч \\
\hline & & УФ, $\lambda=360$ нм, 40 мин \\
\hline \multirow{2}{*}{ ГМА-ДМЭГ } & \multirow{2}{*}{$\begin{array}{c}\text { додеканол : толуол }(27: 4) \\
\text { /циклогексанол }\end{array}$} & $70^{\circ} \mathrm{C}, 3 \mathrm{ч}$ \\
\hline & & УФ, $\lambda=360$ нм, 40 мин \\
\hline \multirow{2}{*}{ Ст } & \multirow{2}{*}{$\begin{array}{c}\text { додеканол : толуол } \\
(52: 8) / \text { циклогексанол } \\
\end{array}$} & $70^{\circ} \mathrm{C}, 3$ ч \\
\hline & & УФ, $\lambda=360$ нм, 40 мин \\
\hline \multirow{2}{*}{ Ст - ДВБ } & \multirow{2}{*}{$\begin{array}{c}\text { ундеканол : толуол }(27: 4) / \\
\text { циклогексанол }\end{array}$} & $70^{\circ} \mathrm{C}, 3$ ч \\
\hline & & УФ, $\lambda=360$ нм, 40 мин \\
\hline
\end{tabular}

МАЛДИ-МС. Масс-спектры МАЛДИ получали путем десорбции/ионизации непосредственно с приготовленных ТСХ пластин с использованием массспектрометра Bruker autofex, снабженного УФ-лазером с длиной волны 355 нм. Запись проводили в режиме положительных ионов с максимальной энергией лазера 8 кДж/м². Пробу исследуемого соединения в виде раствора в ацетонитриле

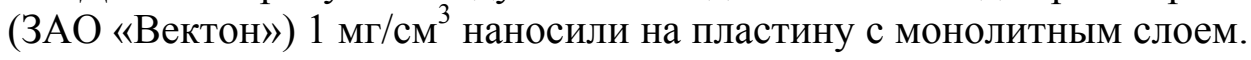


При проведении экспериментов с нанесением традиционной матрицы для МАЛДИ в качестве таковой использовался 1,8,9-антрацентриол, который наносился на пластину в виде раствора $\left(15 \mathrm{mг} / \mathrm{cm}^{3}\right)$ в абсолютизированном ТНФ и высушивался.

Анализ поверхности монолита. Для определения удельной поверхности, объема и размера пор методом БЭТ был использован прибор Micromeritics ASAP-2020 Центра коллективного пользования «Новые нефтехимические процессы, полимерные композиты и адгезивы».

Определение шероховатости поверхности методом атомно-силовой микроскопии. Определение шероховатости поверхности проводили с использованием ACM Solver P47H, NT-MDT, максимальный размер области сканирования 100х100 мкм, $0.02 \div 100$ мкм $^{-1}$.

\section{Обсуждение результатов}

Для получения монолитных сорбентов были опробованы составы полимеризационных смесей, ранее хорошо зарекомендовавшие себя в различных вариантах жидкостной хроматографии [12-15], различные условия проведения полимеризации (термо- и фотоинициируемая), а также 2 вида подложек (стекло, кремний). Приготовленные сорбенты были в первую очередь исследованы на предмет совместимости с режимом МАЛДИ-МС с использованием таких легкоионизирующихся аналитов, как полиэтиленгликоли (ПЭГ), масс-спектры которых регистрируются даже в режиме ЛДИ. Было, однако, обнаружено, что для всех образцов, полученных с использованием только бифункционального мономера (ДМЭГ или ДВБ) при любом из примененных способов полимеризации, не удается получить масс-спектры МАЛДИ ПЭГ, в том числе и с дополнительным добавлением матрицы. Введение в полимеризационную смесь монофункционального мономера меняет ситуацию в лучшую сторону, что позволяет зарегистрировать масс-спектры МАЛДИ образцов ПЭГ непосредственно с пластины с монолитным слоем без дополнительного добавления матричного соединения (рис.3).
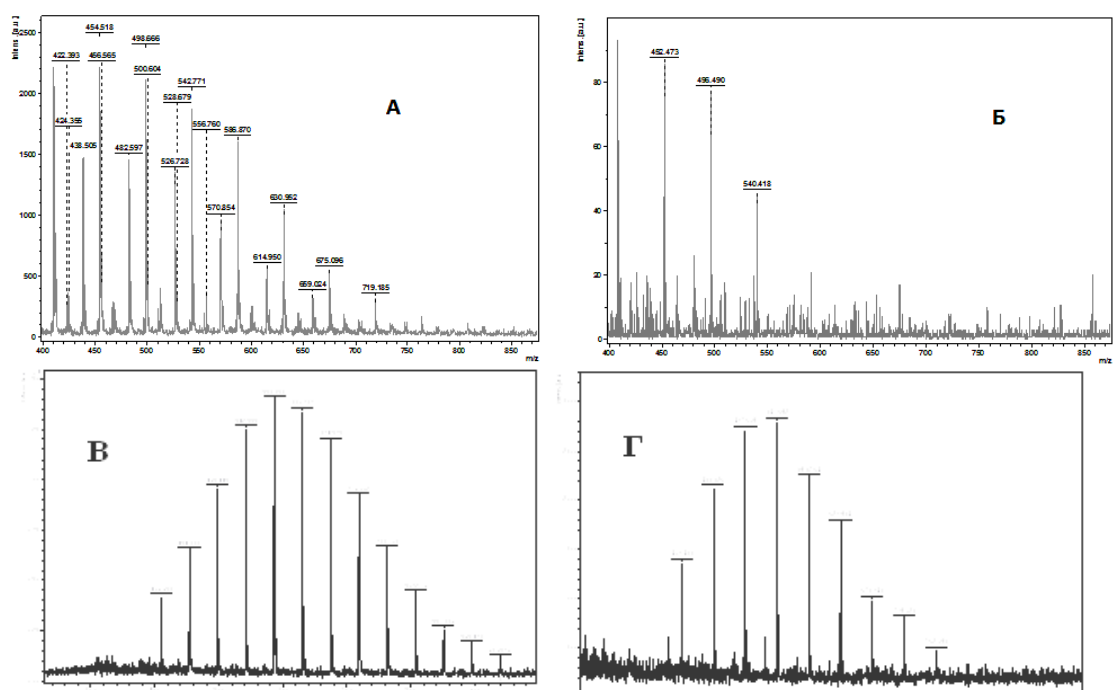

Рис. 3. МАЛДИ масс-спектр стандарта ПЭГ (1 мг/см³), полученный непосредственно с монолитной пластины А: 29\% ГМА + 11\% ДМЭГ + 1\% АИБН, додеканол:толуол (27:4); Б: 14\% ГМА + 26\% ДМЭГ + 1\% АИБН, додеканол:толуол

(27:4), В: 30\% ДВБ + 10\% Ст + 1\% АИБН, деканол:толуол (27:4); Г: 35\% ДВБ + $5 \%$ Ст, ундеканол:толуол (27:4), без добавления МАЛДИ матрицы, условия полимеризации: $70^{\circ} \mathrm{C}, 3$ ч, подложка - покровное стекло 
Сходные результаты были получены при использовании как термо-, так и фотоинициируемой полимеризации, однако в дальнейшем для синтеза монолитных сорбентов была выбрана термически инициируемая полимеризация, поскольку полученные методом фотоинициируемой полимеризации монолитные слои оказались механически непрочными и растрескивались со временем.

Предыдущий опыт работы с монолитными сорбентами в ГХ и ВЭЖХ показывает, что структура и свойства получаемого полимера сильно зависят от относительного количества монофункционального мономера в исходной полимеризационной смеси. Это оказалось справедливо и для ТСХ. В таблице 2 показан состав полимеризационных смесей, использованных для приготовления монолитных слоев.

Было обнаружено, что низкая доля ГМА приводит к образованию механически непрочного монолитного слоя, непригодного для дальнейшего использования в системе МАЛДИ-МС и проведения хроматографических разделений. Наиболее приемлемые результаты показали монолиты с содержанием ГМА от 19 до 29 \%. Для более подробного изучения структурных свойств синтезированных монолитов все указанные выше полимеры были синтезированы в блоке объемом порядка $3 \mathrm{~cm}^{3}$ и затем проанализированы методом низкотемпературной сорбции азота. Результаты приведены в таблицах 3 и 4.

Таблица 2. Составы полимеризационных смесей, использованных для приготовления монолитных ТСХ пластин.

\begin{tabular}{|c|c|c|}
\hline Доля ГМА, \% (масс.)* & Доля ДМЭГ, \% (масс.) & Порообразователь \\
\hline 资 & 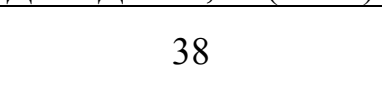 & $\begin{array}{c}\text { додеканол : толуол (52:8) } \\
\text { /циклогексанол }\end{array}$ \\
\hline 4 & 36 & \multirow{6}{*}{$\begin{array}{c}\text { додеканол : толуол (27:4) } \\
\text { /циклогексанол }\end{array}$} \\
\hline 9 & 31 & \\
\hline 14 & 26 & \\
\hline 19 & 21 & \\
\hline 24 & 16 & \\
\hline 29 & 11 & \\
\hline Доля Ст, \% (масс.)* & Доля ДВБ, \% (масс.) & \\
\hline 0 & 40 & \multirow{7}{*}{$\begin{array}{c}\text { додеканол : толуол (52:8) } \\
\text { /циклогексанол }\end{array}$} \\
\hline 5 & 35 & \\
\hline 10 & 30 & \\
\hline 15 & 25 & \\
\hline 20 & 20 & \\
\hline 30 & 10 & \\
\hline 35 & 5 & \\
\hline
\end{tabular}

* от общей массы смеси

Как видно из приведенных данных, площадь удельной поверхности и удельный объем пор уменьшаются с увеличением доли монофункционального мономера в полимеризационной смеси, в то время как средний диаметр пор при этом увеличивается. При этом изменение объема микропор не проявляет какой-то выраженной тенденции, и доля микропор в общем объеме не превышает $1 \%$. Возможность применения таких ТСХ пластин в сочетании с МАЛДИ-МС детектированием наилучшим образом представлена для сорбентов, содержащих от 19 до 29\% (масс.) ГМА в исходной полимеризационной смеси. Так, соотношение сигнал/шум для ПЭГ 400 увеличивается с 9 до 200 при переходе от 14 к 29\% ГМА (рис. 3). Это может быть связано с количеством функциональных групп в структуре полимера, способных поглощать энергию и передавать ее целевому соединению, обеспечивая его ионизацию. Кос- 
венным подтверждением этого факта является невозможность ионизации целевых соединений при использовании сорбента, полученного на основе ДМЭГ без добавления ГМА.

Таблица 3. Структурные характеристики монолитных слоев на основе сополимеров ГМА-ДМЭГ для двух порообразователей: циклогексанол и додеканол:толуол (27:4).

\begin{tabular}{|c|c|c|c|c|c|c|c|c|c|}
\hline \multirow{2}{*}{ № } & \multirow{2}{*}{$\begin{array}{c}\omega \\
\text { ДМЭГ), } \\
\% *\end{array}$} & \multicolumn{2}{|c|}{$\begin{array}{c}\text { Площадь поверхно- } \\
\text { сти по БЭТ, } \text { м }^{2} / \Gamma\end{array}$} & \multicolumn{2}{|c|}{$\begin{array}{c}\text { Общий объем пор } \\
\text { x } 10^{3}, \mathrm{~cm}^{3} / \Gamma\end{array}$} & \multicolumn{2}{|c|}{$\begin{array}{l}\text { Объем микропор } \\
\quad \text { x } 10^{3}, \mathrm{~cm}^{3} / \Gamma\end{array}$} & \multicolumn{2}{|c|}{$\begin{array}{c}\text { Средний диаметр } \\
\text { пор, нм }\end{array}$} \\
\hline & & \begin{tabular}{|} 
цикло- \\
гексанол
\end{tabular} & $\begin{array}{c}\text { додеканол } \\
\text { толуол }\end{array}$ & \begin{tabular}{|} 
цикло- \\
гексанол
\end{tabular} & $\begin{array}{l}\text { додеканол: } \\
\text { толуол }\end{array}$ & : цикло- & \begin{tabular}{|} 
додеканол: \\
толуол
\end{tabular} & \begin{tabular}{|l} 
цикло- \\
гексанол
\end{tabular} & \begin{tabular}{|} 
додеканол: \\
толуол
\end{tabular} \\
\hline 1 & 11 & 33 & 3.76 & 64.4 & 4.22 & 6.65 & 0.50 & 335 & 352 \\
\hline 2 & 16 & 58 & 5.18 & 145.8 & 7.37 & 5.44 & 5.33 & 287 & 215 \\
\hline 3 & 21 & 98 & 8.29 & 207.8 & 13.18 & 19.56 & 2.28 & 213 & 267 \\
\hline 4 & 26 & 154 & 6.77 & 306.8 & 9.51 & 27.32 & 4.46 & 183 & 285 \\
\hline 5 & 31 & 227 & 6.04 & 407.7 & 6.89 & 10.61 & 0.34 & 160 & 213 \\
\hline 6 & 36 & 307 & 29.13 & 489.5 & 30.64 & 55.07 & 16.81 & 144 & 63 \\
\hline 7 & 38 & - & 56 & - & 51.5 & - & 13.74 & - & 56 \\
\hline
\end{tabular}

$*_{\omega}($ (ГМА $), \%=38 \%-\omega($ ДМЭГ), $\%$

Таблица 4. Структурные характеристики монолитных слоев на основе сополимеров Ст-ДВБ для двух порообразователей: деканол:толуол и ундеканол:толуол (27:4).

\begin{tabular}{|c|c|c|c|c|c|c|c|c|c|}
\hline \multirow{2}{*}{ № } & \multirow{2}{*}{$\begin{array}{c}\omega \\
(\text { ДВБ) } \\
\% *\end{array}$} & \multicolumn{2}{|c|}{$\begin{array}{l}\text { Площадь поверх- } \\
\text { ности по БЭТ, м²/г }\end{array}$} & \multicolumn{2}{|c|}{$\begin{array}{c}\text { Общий объем пор } \\
\text { x } 10^{3}, \mathrm{~cm}^{3} / \Gamma\end{array}$} & \multicolumn{2}{|c|}{$\begin{array}{c}\text { Объем микропор } \\
\text { x } 10^{3}, \mathrm{~cm}^{3} / \Gamma\end{array}$} & \multicolumn{2}{|c|}{$\begin{array}{c}\text { Средний диаметр } \\
\text { пор, нм }\end{array}$} \\
\hline & & \begin{tabular}{|l} 
деканол \\
: толуол
\end{tabular} & $\begin{array}{c}\text { ундеканол } \\
\text { толуол }\end{array}$ & $\begin{array}{c}\text { деканол } \\
\text { : толуол }\end{array}$ & $\begin{array}{l}\text { ундеканол } \\
\text { : толуол }\end{array}$ & $\begin{array}{l}\text { деканол } \\
\text { : толуол }\end{array}$ & $\begin{array}{l}\text { ундеканол } \\
\text { : толуол }\end{array}$ & $\mid \begin{array}{c}\text { деканол } \\
\text { : толуол }\end{array}$ & $\begin{array}{l}\text { ундеканол } \\
\text { : толуол }\end{array}$ \\
\hline 1 & 5 & 5.3847 & 4.3433 & 2.360 & 2.045 & 1.62 & 1.27 & 102.327 & 105.429 \\
\hline 2 & 10 & 8.8656 & 1.63 & 11.078 & - & 1.90 & 0.32 & 159.934 & - \\
\hline 3 & 20 & 16.2809 & 2.20 & 23.951 & - & 2.39 & 0.26 & 153.973 & - \\
\hline 4 & 25 & 24.3526 & 4.94 & 38.667 & 3.32 & 3.785 & 1.20 & 126.582 & 149.220 \\
\hline 5 & 30 & 40.5415 & 79.53 & 56.443 & 126.30 & 3.61 & 9.09 & 124.814 & 120.080 \\
\hline 6 & 35 & 74.6301 & 28.56 & 122.056 & 43.23 & 10.54 & 3.63 & 111.527 & 130.259 \\
\hline 7 & 40 & 44.8333 & 27.4834 & 77.923 & 37.56 & 7.89 & 4.56 & 131.491 & 127.315 \\
\hline
\end{tabular}

$* \omega$ (ДВБ), $\%=40 \%-\omega($ Ст $), \%$

Еще одним фактором, оказывающим влияние на возможность десорбции/ионизации соединений, является качество поверхности. Наличие шероховатостей, неравномерность поверхности драматично сказываются на возможности работы в режиме МАЛДИ-МС, а монолиты, содержавшие менее 19\% ГМА, оказались механически непрочными, и манипуляции с ними легко приводили к повреждению поверхности. Аналогичные результаты были получены и для монолитных сорбентов на основе (со)полимеров стирола и дивинилбензола.

Для получения информации о рельефе поверхности монолитные слои были приготовлены на стеклянных подложках (размером 18х18 мм, толщиной 0.130.17 мм) с различным содержанием монофункциональных мономеров и с использованием различных порообразователей (рис. 4): 40\% ДВБ+1\% АИБН, деканол:толуол (52:8) (А); 30\% ДВБ+10\% Ст + 1\% АИБН, ундеканол:толуол (52:8) (Б); 30\% ДВБ + 
10\% Ст+1\% АИБН, деканол:толуол (52:8) (В); 24\% ГМА+16\% ДМЭГ, додеканол:толуол (27:4) (Г); 14\% ГМА+26\% ДМЭГ, 60\% циклогексанол (Д).

a

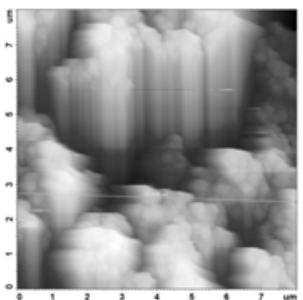

6

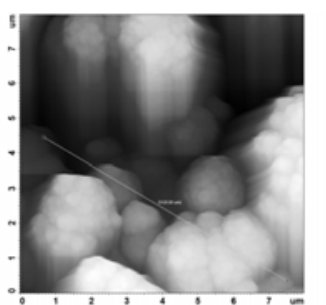

B
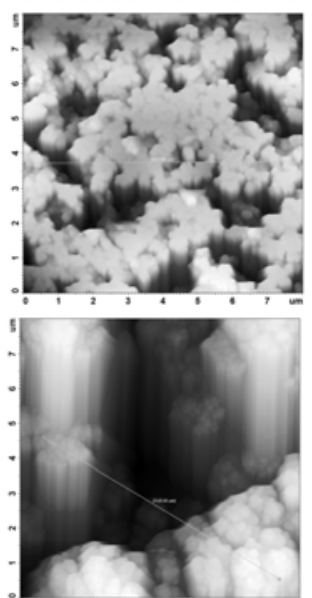

$\Gamma$

д

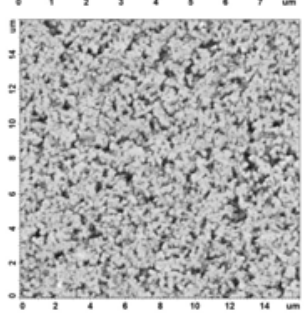

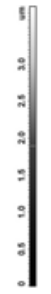
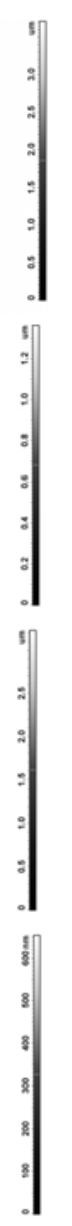
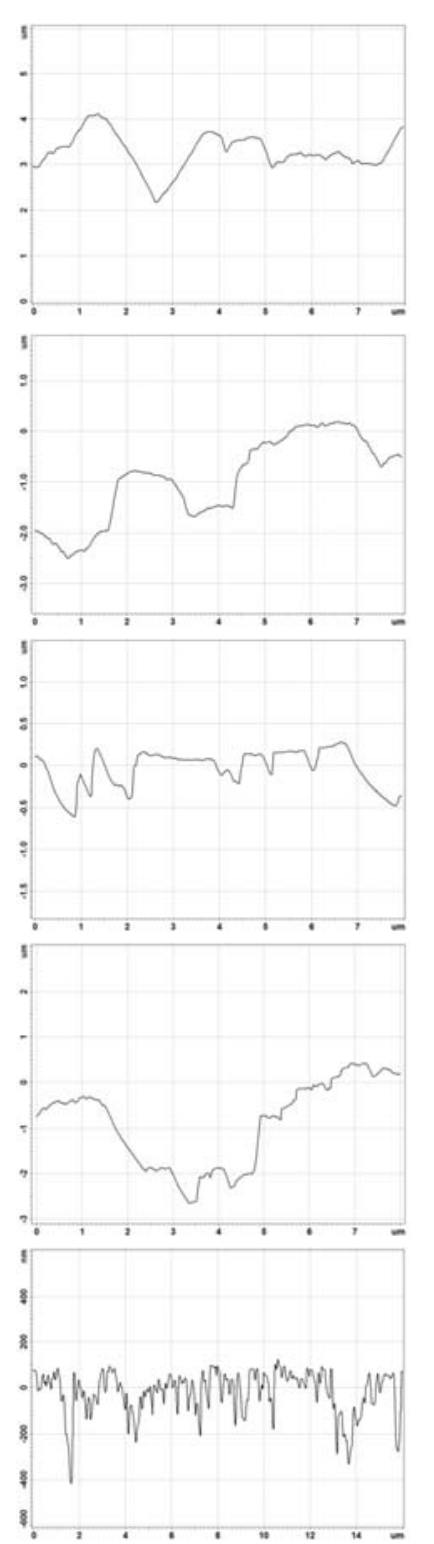

Рис. 4. Топографические АСМ-изображения и микропрофили поверхностей вдоль указанных сечений образцов монолитных слоев: А - 40\% ДВБ+1\% АИБН, деканол:толуол (52:8); Б - 30\% ДВБ+10\% Ст+1\% АИБН, ундеканол:толуол (52:8); В - 30\% ДВБ+10\% Ст+1\% АИБН, деканол:толуол (52:8); Г - 24\% ГМА+16\% ДМЭГ, додеканол:толуол (27:4); Д - 14\% ГМА+26\% ДМЭГ, 60\% циклогексанол при площади сканирования, мкм²: $8 \times 8$ (А-Г), 16×16 (Д)

Поверхность монолитных слоев составов В и Д являлась относительно однородной: при площади сканирования $(8 \times 8)$ мкм² неоднородности рельефа имели модуляции по высоте $R_{y}$ порядка 1.29 и 0.63 мкм соответственно, а средний масштаб шероховатости $R_{a}$ характеризовался размерами 150 и 58 нм соответственно. Изображения поверхностей монолитных слоев составов А, Б и Г имели вид развитых хаотичных структур, средний масштаб шероховатости которых был на два порядка выше, чем для образцов составов В и Д, и соответствовал значениям от 3.34 до 3.73 мкм (рис. 4). Согласно гистограммам распределения по высотам было установ- 
лено, что для образца состава В самая высокая плотность (7000) соответствовала среднему значению шероховатости 150 нм, тогда как для образца состава Е самая высокая плотность (17000) соответствовала среднему значению шероховатости 5060 нм. Функции распределения по высотам отличались от гауссовой наличием левого «хвоста», что свидетельствует об отрицательной асимметрии и несимметричности распределения. Однако, несмотря на это необходимо отметить, что перепад высот на всех участках в случае образца Г не превышал 500 нм.

\section{Заключение}

Использование монолитных пластин, содержащих в своей структуре функциональные группы, способные выполнять роль МАЛДИ матриц, является перспективным направлением в развитии метода ТСХ-МАЛДИ-МС для работы с низкомолекулярными соединениями с массами до 600 Да. В работе показана возможность создания таких пластин, продемонстрированы первые результаты по десорбции/ионизации соединений с массами порядка 400 Да. Приготовлены монолитные пластины на основе (со)полимеров ГМА и ДМЭГ с содержанием ГМА от 0 до 29\% и Ст и ДВБ с содержанием Ст от 0 до $35 \%$. Наилучшие результаты удалось получить для пластин с содержанием ГМА от 19 до 29 \% и с содержанием стирола 5-20\%. Отмечено, что отсутствие монофункционального мономера (глицидилметакрилат или стирол) в полимеризационной смеси приводит к подавлению ионизации аналитов и невозможности использования таких пластин в режиме МАЛДИ-МС. Предложенный в работе метод получения МАЛДИ-МС-ТСХ спектров позволяет исключить один из наиболее трудоемких этапов процесса, связанный с приготовлением и нанесением МАЛДИ матрицы на ТСХ платины.

\section{Работа выполнена в рамках Государственного задания ИНХС РАН}

\section{Список литературы}

1. Huaxin Dai, Xiao-Qi Zhang, Harasymow S., Roumeliotis S. et al. // International Journal of Mass Spectrometry. 2014. Vol. 371. pp. 8-16.

2. Vrkoslav V., Muck A., Cvačka J., Svatoš A. // J. Am Soc Mass Spectrom. 2010. Vol. 21. pp. 220-231.

3. Fuh M.M., Heikaus L., Schlüter H., $J$. Mass Spectrom., 2016, http://dx.doi.org/10.1016/j.ijms.2016.10.004 In press.

4. Vestal M., Hayden K., International Journal of Mass Spectrometry, 2007, Vol. 268, Iss. 2-3. pp. 83-92.

5. Budnik B.A., Moyer S.C., Pittman J.L., Ivleva V.B. et al. // International Journal of Mass Spectrometry. 2004.Vol. 234, Issues 1-3. pp. 203-212.

6. Xuan Su, Huan-Ying Zhou, Feng-Chun Chen, Bao-Xiang Gao et al. // International Journal of Mass Spectrometry. 2013. Vol. 338. pp. 39-44.
7. Mullens C.P., Anugu S.R., Gorski W., Stephan B.H. // International Journal of Mass Spectrometry. 2011. Vol. 308. Iss. 2-3. pp. 311315.

8. Hong-zhi Tang, Ya-lin Ma, Fei Liu, Fang Liu et al. // International Journal of Mass Spectrometry. 2017. Vol. 417. pp. 34-39.

9. Esparza C., Borisov R.S., Varlamov A.V., Zaikin V.G. // Journal of Chromatography A. 2016. Vol. 1470. pp. 118-122.

10. Leriche E., Hubert-Roux M., Grossel M.C., Lange C.M. et al. // Analytica Chimica Acta. 2014. Vol. 808. pp. 144-150.

11. Ferey J., Da Silva D., Lafite P., Daniellou R. et al. // Talanta. 2017. Vol. 170.pp. 419-424.

12. Кучеренко Е.В., Мельник Д.М., Королев А.А., Канатьева А.Ю. и др. // Журнал физической химии. 2015. Т. 89. № 9. С. 14781483

13. Kurganov A., Victorova E., Kanateva A. // J. Sep. Sci. 2015. Vol. 38. Is. 13. pp. 22232228. DOI: $10.1002 /$ jssc. 201500211 
14. Викторова Е.Н., Королев А.А., Ибрагимов Т.Р., Канатьева А.Ю. // ВМС. 2013. Т. 55. No 3. pp. 312-320.

\section{References}

1. Huaxin Dai, Xiao-Qi Zhang, Harasymow S., Roumeliotis S. et al., International Journal of Mass Spectrometry, 2014, Vol. 371, pp. 8-16.

2. Vrkoslav V., Muck A., Cvac`ka J., Svatoš A., J. Am Soc Mass Spectrom., 2010, Vol. 21, pp. 220-231.

3. Fuh M.M., Heikaus L., Schlüter H., J. Mass Spectrom., $\quad 2016$, http://dx.doi.org/10.1016/j.ijms.2016.10.004 In press.

4. Vestal M., Hayden K., International Journal of Mass Spectrometry, 2007, Vol. 268, Iss. 2-3, pp. 83-92.

5. Budnik B.A., Moyer S.C., Pittman J.L., Ivleva V.B. et al. // International Journal of Mass Spectrometry, 2004, Vol. 234, Is. 1-3, pp. 203-212.

6. Xuan Su, Huan-Ying Zhou, Feng-Chun Chen, Bao-Xiang Gao et al., International Journal of Mass Spectrometry, 2013, Vol. 338, pp. 39-44.

7. Mullens C.P., Anugu S.R., Gorski W., Stephan B.H., International Journal of Mass Spectrometry, 2011, Vol. 308, Is. 2-3, pp. 311315.

8. Hong-zhi Tang, Ya-lin Ma, Fei Liu, Fang Liu et al., International Journal of Mass Spectrometry, 2017, Vol. 417, pp. 34-39.

Кучеренко Елизавета Владимировна - асп. каф. аналитической химии, МГУ им. М.В. Ломоносова, химический факультет, Москва

Канатьева Анастасия Юрьевна - к.х.н., в.н.с. лаб. спектральных и хроматографических методов, ИНХС РАН, Москва

Курганов Александр Александрович - д.Х.н., г.н.с. лаб. спектральных и хроматографических методов, ИНХС РАН, Москва

Борисов Роман Сергеевич - к.х.н., зав. лаб. спектральных и хроматографических методов, ИНХС РАН, Москва

Пирогов Андрей Владимирович - д.х.н., в.н.с. каф. аналитической химии, МГУ им. М.В. Ломоносова, химический факультет, Москва
15. Korolev A., Victorova E., Ibragimov T., Kanatyeva A. et al. // J. Sep. Sci. 2012. Vol. 35. Is. 8. pp. 957-963. April 2012 DOI:10.1002/jssc.201101042

9. Esparza C., Borisov R.S., Varlamov A.V., Zaikin V.G., Journal of Chromatography A, 2016, Vol. 1470, pp. 118-122.

10. Leriche E., Hubert-Roux M., Grossel M.C., Lange C.M. et al., Analytica Chimica Acta, 2014, Vol. 808, pp. 144-150.

11. Ferey J., Da Silva D., Lafite P., Daniellou R. et al., Talanta, 2017, Vol. 17, pp. 419-424.

12. Kucherenko E.V., Melnik D.M., Korolev A.A., Kanateva A.Yu. et al., Russian Journal of Physical Chemistry A, 2015, Vol. 89, No 9, pp. 1688-1692.

13. Kurganov A., Victorova E., Kanateva A., J. Sep. Sci., 2015, Vol. 38, Is. 13, pp. 22232228. DOI: $10.1002 /$ jssc. 201500211

14. Viktorova E.N., Korolev A.A., Ibragimov T.R., Kanat'eva A.Yu. et al., Polymer Science, Ser. A, 2013, Vol. 55, No 3, pp. 204-211.

15. Korolev A., Victorova E., Ibragimov T., Kanatyeva A. et al., J. Sep. Sci., 2012, Vol. 35, Is. $8, \quad$ pp. 957-963. April 2012 DOI:10.1002/jssc.201101042

16. Korolev A., Victorova E., Ibragimov T., Kanatyeva A. et al., J. Sep. Sci., 2012, Vol. 35, Is. $8, \quad$ pp. 957-963. April 2012 DOI:10.1002/jssc.201101042

Kucherenko Elizaveta V. - PhD student, MSU, Faculty of Chemistry, Russia, Moscow

Kanateva Anastasiia Yu. - PhD, leading researcher, lab. for spectral and chromatographic methods, A.V. Topchiev Institute of Petrochemical Synthesis, RAS (TIPS RAS), Moscow, kanatieva@ips.ac.ru

Kurganov Alexander A. - DSc, chief researcher, lab. for spectral and chromatographic methods, A.V.Topchiev Institute of Petrochemical Synthesis, RAS (TIPS RAS), Moscow

Borisov Roman S. - PhD, the head of the lab. for spectral and chromatographic methods, A.V.Topchiev Institute of Petrochemical Synthesis, RAS (TIPS RAS), Moscow

Pirogov Andrey V. - DSc, leading researcher, MSU, Faculty of Chemistry, Russia, Moscow 